\title{
EVIDENCIAÇÃO DA APLICAÇÃO DO VALOR ADICIONADO EM AÇÕES DE RESPONSAB ILIDADE SOCIOAMBIENTAL: UM ESTUDO REALIZADO COM BASE NOS BALANÇOS SOCIAIS DA PETROBRAS S.A. NO PERÍODO DE 1998 A 2009
}

\author{
Maria Solange de Moura \\ Bacharel em Ciências Contábeis pela Faculdade Santa Catarina - FASC \\ solangemoura45@hotmail.com
}

Ana Paula Ferreira da Silva

Mestre em Administração pela Universidade Federal de Pernambuco - UFPE Professora do curso de Ciências Contábeis da Faculdade Boa Viagem - FBV

e da Faculdade Santa Catarina - FASC

anapafesilva@hotmail.com

\section{James Anthony Falk}

Doutor em Public Administration pela University of Georgia - UGA

Professor do Mestrado Empresarial da Faculdade Boa Viagem - FBV

thefalks@terra.com.br

\section{RESUMO}

Este trabalho apresenta uma discussão sobre a evidenciação da aplicação do valor adicionado em ações socioambientais desenvolvidas pela Petrobras, por meio do Balanço Social. Para a realização deste trabalho, foram coletados dados documentais contidos nos Balanços Sociais da Petrobras, no período de 1998 a 2009. Por meio da análise, fica evidente que, apesar do aumento monetário do valor adicionado durante o período estudado, não ocorreu um acompanhamento proporcional do investimento da riqueza gerada em ações de responsabilidade socioambiental. As descobertas da pesquisa também revelaram que: a maior parcela do valor adicionado aplicado no social foi voltada para os funcionários, com destaque em áreas, tais como educação, alimentação, previdência privada e participação nos lucros e resultados. O meio ambiente é o agente beneficiado pelas ações sociais da Petrobras S.A, com a menor fatia do valor adicionado investido no campo socioambiental, ou seja, recebeu, por meio das ações, menos de $0,5 \%$ do valor adicionado gerado durante o período de 1998 a 2009. Esse parâmetro chamou a atenção, pelo fato de se esperar que a Petrobras investisse mais recursos na área ambiental, em razão dos riscos que sua atividade operacional pode gerar para o meio ambiente.

Palavras-chave: Balanço social; Evidenciação; Indicadores sociais; Petrobras; Responsabilidade socioambiental; Valor adicionado.

\section{DISCLOSURE ON THE APPLICATION OF ADDED VALUE WITH ACTIONS OF SOCIO- ENVIRONMENTAL RESPONSABILITY: A STUDY BASED ON THE SOCIAL BALANCE SHEET PUBLISHED BY PETROBRAS, S.A. FOR THE PERIOD 1998 TO 2009.}

\begin{abstract}
This paper presents a discussion on the disclosure of the application of Added Value with socioenvironmental actions developed by Petrobras as seen through its Social Balance Sheet. To develop this paper documentary evidence was collected from the Social Balance Sheets of Petrobras for the period of 1998 to 2009. Through data analysis, it is evident that despite the increased monetary added value observed during the study period, there was no proportional investment of the wealth generated in socio-environmental responsibility actions. The survey findings also revealed that the largest share of added value applied to the social aspect was directed to employees, especially in areas such as education, food, private pensions and profit sharing results. The Environment is the agent of social benefit by Petrobras S.A. with the lowest share of added value invested in the socio-environmental field, having received, through applied actions, less than $0.5 \%$ of the added value generated during the period 1998 to 2009. This parameter has drawn special attention from the fact that Petrobras is expected to invest more resources in the environmental area due to the high operational risks that its activities may cause the environment.
\end{abstract}

Key words: Added value; Disclosure; Petrobrás; Social balance; Socio-environmental responsibility; Social indicators. 
Evidenciação da aplicação do valor adicionado em ações de responsabilidade socioambiental: um estudo realizado com base nos balanços sociais da Petrobrás S.A. no período de 1998 a

\section{INTRODUÇÃO}

A responsabilidade socioambiental está ligada a maneira de como se comportam as empresas, como elas abstraem do meio ambiente, e como está a relação para com os componentes de interesse a essa ação, conhecidos por "stakeholders". Isto denota como a empresa está sendo governada, e seus reflexos nos resultados econômicos e financeiros.

O Balanço Social é um demonstrativo, que além de informar quais são as áreas de investimentos sociais de uma instituição voltados para os agentes: funcionários, sociedade e meio ambiente, também apresenta informações sobre o valor adicionado a distribuir, bem como sua distribuição para os diversos agentes que colaboraram para a geração da riqueza naquele período.

A Petrobras é uma empresa de capital aberto, cujo acionista majoritário é o Governo do Brasil. É, portanto, uma empresa estatal de economia mista. Foi fundada em 03 de outubro de 1953 e está sediada no Rio de Janeiro (Petrobras, 2010). A Petrobras é considerada como a maior empresa do país e a segunda no ranking das maiores petrolíferas de capital aberto do mundo. Em valor de mercado, foi considerada em 2010, a segunda maior empresa do continente americano e a quarta maior do mundo (Estadão, 2010). Além disso, em 2010, a Petrobras já movimentava 10\% do PIB brasileiro (Landim, 2010).

A posição mercadológica da Petrobras no Brasil e no mundo com relação ao PIB (geração de riqueza), bem como o fato da atividade fim dessa companhia necessitar de investimentos para renovação dos recursos naturais, surge a seguinte indagação: quanto da riqueza gerada pela Petrobras é gasto com ações voltadas para o social.

O objetivo principal desde estudo é identificar quanto do valor adicionado (riqueza gerada) da Petrobras é aplicado em ações de responsabilidade socioambiental, bem como quais são as áreas de aplicação dessa parcela para os agentes beneficiados (funcionários, sociedade e meio ambiente) são divulgadas nos Balanços Sociais da companhia em estudo. A fim de alcançar o objetivo geral, foram definidos objetivos específicos, que são de identificar: a) as prioridades de investimento em ações de Responsabilidade socioambiental realizadas pela Petrobras; b) quais dos principais indicadores sociais são utilizados para evidenciar as ações de Responsabilidade Socioambiental da empresa; c) qual proporção do valor adicionado anualmente é gasto com ações de Responsabilidade Socioambiental pela Petrobras S.A.

\section{FUNDAMENTAÇÃO TEÓRICA}

Esta seção apresenta uma revisão da literatura que fundamenta os conceitos empregados nesta pesquisa. Assim sendo, a fim de pesquisar sobre a aplicação da riqueza gerada pela Petrobras, faz-se necessário discorrer sobre as seguintes vertentes: responsabilidade socioambiental, valor adicionado e balanço social.

\subsection{Responsabilidade socioambiental: conceito e origem}

Conforme Correia e Medeiros (2003), a discussão sobre a temática Responsabilidade Social teve sua origem no estudo publicado por Howard Bowen, em 1953, nos Estados Unidos. Um pouco mais de uma década depois, a Responsabilidade Social começou a ser discutida na Europa, e ainda nesse período a sociedade iniciou a cobrança por maior Responsabilidade Social das empresas, por meio do qual, consolidou-se a própria necessidade de divulgação dos chamados balanços e relatórios sociais. (Rizzi, 2002).

A figura 1 mostra a evolução do conceito de Responsabilidade Social, mediante visão de alguns dos estudiosos no assunto.

\begin{tabular}{|c|l|}
\hline AUTORES & CONCEITUAÇÃO \\
\hline $\begin{array}{c}\text { Bowen } \\
(1953)\end{array}$ & $\begin{array}{l}\text { Obrigação do empresário de adotar políticas, tomar decisões e acompanhar linhas } \\
\text { de ação desejáveis, segundo os objetos e valores da sociedade. }\end{array}$ \\
\hline
\end{tabular}

Revista de Gestão Social e Ambiental - RGSA, São Paulo, v. 6, n. 2, p. 93-105, maio/ago. 2012. 


\begin{tabular}{|c|l|}
\hline $\begin{array}{c}\text { Friedman } \\
(1970)\end{array}$ & $\begin{array}{l}\text { Responsabilidade social e um comportamento antimaximização de lucros, assumido } \\
\text { para beneficiar outros que não os acionistas da empresa. Portanto, existe somente } \\
\text { uma responsabilidade da empresa: utilizar seus recursos e organizar suas atividades } \\
\text { com o objetivo de aumentar seus lucros, seguindo as regras do jogo de mercado. }\end{array}$ \\
\hline $\begin{array}{c}\text { Kugel } \\
(1973)\end{array}$ & $\begin{array}{l}\text { Desenvolvimento do conceito de responsabilidade social: acompanhou a própria } \\
\text { evolução dos programas sociais estabelecidos pelas empresas americanas. Os } \\
\text { executivos passaram a aceitar a necessidade de realizar certas ações e procuraram } \\
\text { fazer com que fossem componentes regulares das operações das empresas. }\end{array}$ \\
\hline $\begin{array}{c}\text { Petit } \\
(1976)\end{array}$ & $\begin{array}{l}\text { Ética do lucro dando lugar à ética da responsabilidade social: demandas } \\
\text { empresarial, ou seja, com funções especificamente econômicas. }\end{array}$ \\
\hline $\begin{array}{c}\text { Zenisek } \\
(1979)\end{array}$ & $\begin{array}{l}\text { Responsabilidade social como uma preocupação das empresas com as expectativas } \\
\text { do público. Seria, então, a utilização de recursos humanos, físicos e econômicos } \\
\text { para fins sociais mais amplos, e não simplesmente para satisfazer interesses de } \\
\text { pessoas ou organizações em particular. }\end{array}$ \\
\hline
\end{tabular}

Figura 1: Síntese conceitual de responsabilidade social

Fonte: Hatz, (2001, p. 39)

\subsection{Valor adicionado: conceito, origem e importância}

Utilizando a premissa do Produto Interno Bruto (PIB), como a soma de todos os serviços e bens produzidos em uma região específica (país, estado, cidade, continente) e em um determinado período (mês, semestre, ano), Tinoco (1984, p.54) conceitua o valor adicionado como sendo "[...]a diferença entre o valor bruto da produção e os consumos intermediários nessa etapa". Cunha et al (2009, p.31) definem o valor adicionado: "[...]como sendo a diferença entre o valor da produção e os consumos intermediários (compras a outras empresas) num determinado período"

De acordo com a visão da microeconomia, o conceito de "valor adicionado" é recente, foi considerado a partir dos anos 1950, quando começou a ser utilizado por algumas companhias da Inglaterra (Cosenza, 2003). Nesta mesma década, o governo britânico estabeleceu uma campanha a favor de planos de pagamento de incentivos, por meio do valor adicionado, visando uma reformulação dos sistemas de determinação dos salários, (Hopwood; Buchell, 1982).

Segundo Rahman (apud Cosenza, 2003, p. 8), após vinte anos, ou seja, na década de 1970, "[...]o interesse pela informação do valor adicionado se estendeu amplamente entre as empresas britânicas”. A repercussão foi tanta que o Accounting Standards Steering Committee, intitulado The Corporate Report, publicou em 1975 um documento sobre o valor adicionado, demonstrando o desejo de reunir as informações econômicas e sociais em um relatório, unificando-o, para o entendimento dos investidores e dos assalariados. (Chan, Silva, Martins, 2007). A geração e distribuição do valor adicionado gerado durante um determinado período, bem como a sua distribuição, são evidenciados na Demonstração de Valor Adicionado (DVA). Kroetz (2000, p.42) afirma que por meio da DVA "[...]é possível perceber a contribuição econômica da entidade para cada segmento com que ela se relaciona. Constitui-se no Produto Interno Bruto (PIB) produzido pela organização".

\subsection{Balanço social: conceito, origem, importância e modelo Ibase}

No Brasil, a temática balanço social começou a ser discutida na década de 1970. Contudo, o balanço social (BS) da Nitrofétil, empresa estatal situada na Bahia, realizado em 1984, é considerado o primeiro documento brasileiro do gênero que carrega o nome de balanço social. Concomitantemente, estava sendo realizado o BS do Sistema Telebrás, publicado em meados da década de 1980. O do Banespa, realizado em 1992, também compõe a lista das empresas precursoras em BS no Brasil. (Ibase, 2008).

O Instituto Ibase, por sua vez, foi a primeira organização não-governamental a publicar seu balanço. Após Herbert de Souza, o Betinho, então presidente da entidade, foi lançada uma 
Evidenciação da aplicação do valor adicionado em ações de responsabilidade socioambiental: um estudo realizado com base nos balanços sociais da Petrobrás S.A. no período de 1998 a

campanha pela divulgação voluntária do balanço social. Sobre esse acontecimento, o Ibase (2008, p. 18) afirma que:

A questão da responsabilidade social das empresas e da publicação anual do balanço social ganhou destaque na mídia e uma intensa visibilidade nacional quando Betinho escreveu o artigo "Empresa pública e cidadã", em março de 1997. A partir dessa discussão e da grande repercussão nacional do tema, o Ibase lançou, em 16 de junho de 1997, uma campanha pela divulgação anual do balanço social das empresas, trazendo a mensagem de que esse seria o "primeiro passo para uma empresa tornar-se uma verdadeira empresa cidadã".

O balanço social é um documento usado pelas organizações para avaliação de desempenho, demonstrando todas as ações sociais desenvolvidas durante um período. O Emerson Kapaz, do Instituto Ethos, em entrevista concedida a Mendonça (2004, p.10), comentou que o balanço social pode ser medido e demonstrado pelo resultado das ações sociais desenvolvidas por uma organização, quando afirmou:

O mais praticado é a publicação do relatório conhecido como Balanço Social, que nos últimos anos tem evoluído quanto aos indicadores e metodologia de apuração de resultados conquistados, graças à orientação de organizações como Instituto Ethos, IBASE etc. Em minha opinião, essa ferramenta - que em $\mathrm{O}$ Boticário chamamos de Relatório de Responsabilidade Corporativa - é a forma mais eficaz e transparente de demonstração de resultados.

O balanço social não é apenas uma demonstração direcionada à sociedade, ela também é uma ferramenta gerencial, servindo na unificação de dados qualitativos e quantitativos para a política administrativa, assim como nas relações existentes entre entidade e meio ambiente. A partir deste aspecto pode ser comparado e analisado com confiabilidade, mediante necessidades dos usuários internos, servindo de instrumento ao controle para tomadas de decisões.

Em resumo, o balanço social define as características e as práticas de responsabilidade sociais adotadas pelas empresas. Pois, este instrumento é o resultado que será disponibilizado ao público sobre as ações sociais da empresa junto aos seus diversos parceiros: sejam empregados, fornecedores, clientes, comunidade, meio ambiente, entre outros.

No Brasil, há, basicamente, a utilização de três tipos de modelos de relatórios de responsabilidade ou Balanço Social, são eles: o do Instituto Brasileiro de Análises Sociais e Econômicas (Ibase), do Instituto Ethos de Empresas e Responsabilidade Social (Ethos) e o internacional, sugerido pela Global Reporting Initiative (GRI). Sendo o primeiro e mais utilizado na década de 1990, pois, segundo Custódio e Moya (2007), este modelo tem como principais características: a simplicidade e a capacidade de penetração em diversos segmentos da sociedade, podendo ser utilizado como instrumento de demonstração da sua contribuição ao desenvolvimento sustentável.

O modelo Ibase, segundo Torres (2001, p. 26) possui quatro particularidades: a) Foi criado com base na iniciativa de uma organização não-governamental (ONG), que cobra transparência e efetividade nas ações sociais e ambientais das empresas; b) Separa as ações e os benefícios obrigatórios dos realizados de forma voluntária pelas empresas; c) É basicamente quantitativo; d) Se for corretamente preenchido, pode permitir a comparação entre diferentes empresas e a avaliação de uma mesma corporação ao longo dos anos.

As informações colhidas do Ibase (2008) mostram que o seu modelo de BS nos últimos dez anos passou por duas revisões, que sofreram alterações para os diversos públicos: organizações sociais, sindicatos, consultores e empresas. O Modelo Ibase de balanço social é composto por 43 indicadores quantitativos e oito indicadores qualitativos, organizados em sete categorias ou partes 
descritas a seguir.

1 - Formação financeira ou base de cálculo - informam os valores da Receita Líquida, do Resultado Operacional e da Folha de Pagamento Bruto. Tais valores servirão de base para o cálculo dos percentuais nos outros itens.

2 - Indicadores sociais internos ou indicadores laborais - Relacionam todos os gastos com os funcionários da empresa, tais como alimentação, encargos sociais compulsórios, previdência, saúde, educação, creches e participação nos resultados, etc.

3 - Indicadores sociais externos - Apresentam os gastos realizados na área social em benefício da sociedade. Entre eles tem-se: patrocínio, alimentação, saúde, doações, etc.

4 - Indicadores ambientais - Estes itens apresentam os dados dos gastos realizados em projetos de investimentos em meio ambiente.

5 - Indicadores de corpo funcional - São informações referentes aos funcionários da empresa, tais como quantidade e perfil dos colaboradores (números de empregados, números de admitidos, número de mulheres em cargo de chefia, número de empregados portadores de deficiência), além de outras informações consideradas relevantes ao exercício da responsabilidade social.

6 - Informações relevantes quanto ao exercício da cidadania empresarial - Informações que demonstram a preocupação pela conservação de um ambiente de trabalho e da participação dos funcionários em projetos e benefícios da empresa. Abrange informações, tais como a relação entre a maior e menor remuneração, o número de acidentes de trabalho, o fato de a empresa ouvir os funcionários, etc.

7 - Outras Informações - Informações que achar relevantes com relação ao seu aspecto social.

É neste grupo que se tem outras informações importantes quanto ao exercício da responsabilidade social, ética e transparência.

\section{MÉTODO DE PESQUISA}

Essa seção apresenta o procedimento metodológico utilizado no decorrer da pesquisa. São eles: método, tipologias do estudo, instrumento de coleta de dados e análises de dados de coleta. Tomando o estudo de caso como uma pesquisa em profundidade de uma unidade de interesse, podendo ser ela única ou múltipla, o estudo em questão será elaborado particularmente na Petrobras, portanto, denominado único. Martins (2008, p. 12) na apresentação do seu livro específica:

O trabalho de campo de uma pesquisa orientada pela estratégia de um Estudo de Caso é precedido pela exposição do problema de pesquisa questões orientadoras - do enunciado de proposições - teses - que compõem a teoria preliminar que será avaliada a partir dos achados da pesquisa; de uma plataforma teórica. De um detalhado planejamento de toda a investigação, destacando-se a construção de um protocolo do caso, contendo descrição dos instrumentos de coleta de dados e evidências, estratégias de coleta e análise dos dados.

Como na classificação proposta por Beuren et al (2008), este estudo é classificado quanto:

a) Aos objetivos: em uma pesquisa exploratória, descritiva, visando demonstrar quanto e como da riqueza gerada é aplicada em ações voltadas para gestão socioambiental da Petrobras. Entende sobre a pesquisa descritiva que ela: "[...]observa, registra, analisa e correlaciona fatos ou fenômenos (variáveis) sem manipulá-los" (Cervo, Bervian, 2006, p.66). Além disso, Vergara (2000, p. 47) analisa que: "[...]o estudo descritivo não tem o compromisso de explicar os fenômenos que descreve".

b) Aos procedimentos: em uma pesquisa documental. Marconi e Lakatos (2003, p. 174-175) afirmam: "A característica da pesquisa documental é que a fonte de coleta de dados está restrita a documentos escritos ou não". No caso esse estudo, a fonte de dados primários 
Evidenciação da aplicação do valor adicionado em ações de responsabilidade socioambiental: um estudo realizado com base nos balanços sociais da Petrobrás S.A. no período de 1998 a

utilizada foram os balanços sociais no modelo Ibase da Petrobras, bem como a demonstração de valor adicionado, no período de 1998 a 2009.

c) A abordagem: um estudo qualitativo e quantitativo. É quantitativa por procurar identificar quanto da riqueza gerada (valor adicionado) é aplicada em ações sociais para evidenciar a responsabilidade socioambiental da Petrobras; e qualitativa, por investigar quais são os indicadores (áreas de ações) utilizados para evidenciar as práticas de responsabilidade socioambiental por agente beneficiado (funcionário, sociedade e meio ambiente).

A coleta de dados foi realizada pela aplicação de um formulário próprio, objetivando a padronização de dados, e facilidade para análise e a apresentação das descobertas da pesquisa. $\mathrm{O}$ formulário foi elaborado com base numa análise preliminar dos Balanços Sociais (BSs), bem como do valor adicionado a distribuir da Petrobras, no período de 1998 a 2009. Todos os dados documentais foram coletados no sítio da Petrobras. O instrumento de coleta de dados foi constituído de seis grupos de perguntas, como se segue:

\begin{tabular}{|c|l|}
\hline GRUPO & INFORMAÇÕES COLETADAS \\
\hline 1 & O valor adicionado a distribuir no período \\
\hline 2 & $\begin{array}{l}\text { Valores totais investidos por grupo beneficiado, bem como a representação deste sobre o } \\
\text { valor total investido no social. }\end{array}$ \\
\hline 3 & $\begin{array}{l}\text { Investimentos voltados para o público interno e os indicadores sociais utilizados para } \\
\text { evidenciar tais investimentos bem como o seu ranking. O grupo inclui informações sobre } \\
\text { os indicadores do corpo funcional, que evidencia a relação da organização com os seus } \\
\text { colaboradores. }\end{array}$ \\
\hline 5 & $\begin{array}{l}\text { Investimentos voltados para o público externo (sociedade) e os indicadores sociais } \\
\text { utilizados para evidenciar tais investimentos e o seu ranking. }\end{array}$ \\
\hline 6 & $\begin{array}{l}\text { Vertentes do balanço social conhecida como balanço ambiental. Indicadores utilizados } \\
\text { para evidenciar a responsabilidade ambiental, bem como o ranking dos investimentos } \\
\text { ambientais. }\end{array}$ \\
\hline $\begin{array}{l}\text { Indicadores utilizados para evidenciar a responsabilidade social da organização, bem } \\
\text { como o seu ranking. }\end{array}$ \\
\hline
\end{tabular}

Figura 2: Estrutura do instrumento de coleta de dados documentais

Fonte: Elaboração própria das autoras

\section{RESULTADOS DO ESTUDO EMPÍRICO}

Esta seção do artigo apresenta os resultados obtidos na pesquisa documental realizada nos balanços sociais da Petrobras.

\subsection{Investimentos da riqueza gerada no social}

Os achados da pesquisa revelaram que a Petrobras manteve um crescimento constante com relação à riqueza gerada em termos monetários, durante o período de 1998 a 2009 (Vide figura 3). Isto pode ser observado pela linha reta da tendência observada no período. 


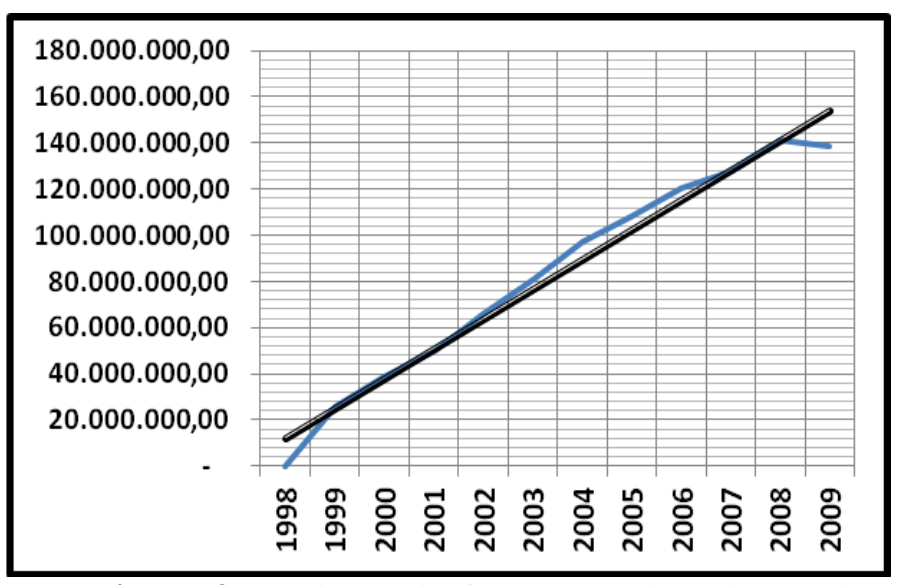

Figura 3: Evolução da riqueza gerada pela Petrobras

Fonte: Pesquisa documental, 2010

A figura 4 mostra que os investimentos da empresa foram distribuídos em indicadores diversificados, contudo, em recursos fora do alcance analítico da área social. Isto torna clara a empregabilidade desproporcionada em relação as necessidades de comunidades sociais e não sociais, em proporções mensuráveis. As aplicações são quase constantes em todos os anos em estudo, com exceção do primeiro ano.

A figura 5 demonstra que houve uma aplicação em investimentos em ações sociais voltadas para os três agentes beneficiados (funcionários, sociedade e meio ambiente), porém, é notória a maior aplicação quanto aos recursos aos funcionários, a única área de investimento interno no primeiro ano. Houve uma oscilação com proporções em desníveis por alguns anos, mais a partir de 2005 a proporção de aplicação para todos os anos seguintes tornou-se quase constante.

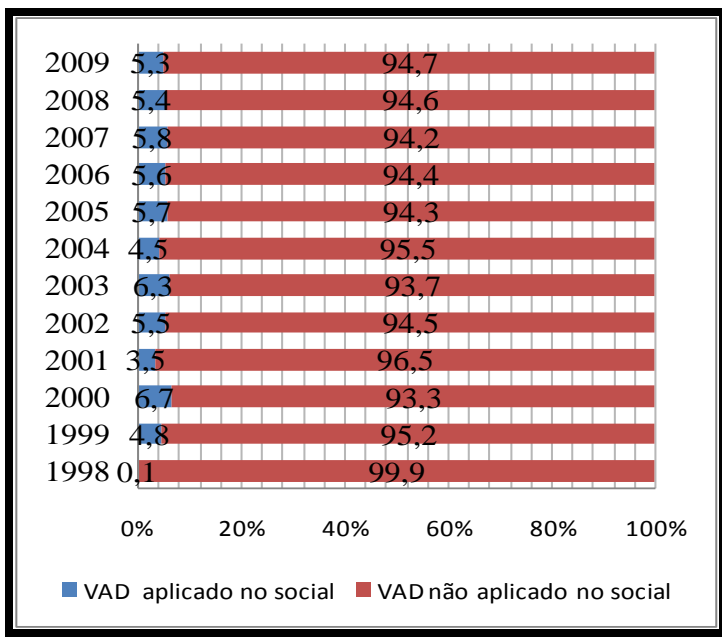

Figura 4: Valor adicionado em ações de responsabilidade social em percentagem

Fonte: Pesquisa documental, 2010

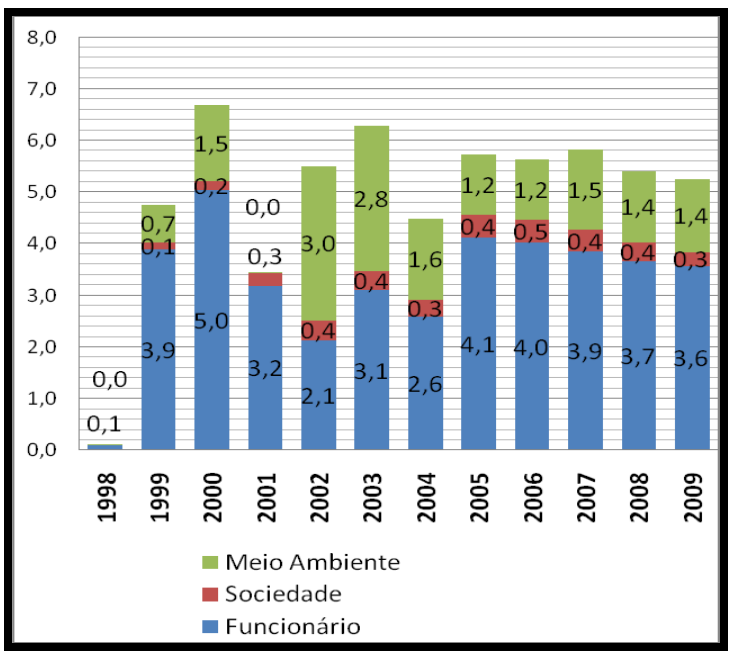

Figura 5: Valor adicionado (\%) em ações de responsabilidade social por agente.

Fonte: Pesquisa documental, 2010

\subsection{Indicadores de responsabilidade social usados pela Petrobras}

$\mathrm{Na}$ tabela 1, pode-se observar um grande foco na existência de práticas de produção baseadas em uma gestão ambiental sustentável. É de se esperar que a Petrobras, neste aspecto, investisse em projetos ambientais, pois poderiam garantir a continuidade da existência dos recursos ambientais, para assim obter a sustentabilidade. O indicador denominado "total dos investimentos em meio ambiente" está presente em todos os 12 (doze) exercícios estudados. Em 9 dos 12 exercícios aparecem dois indicadores de maneira igual. São eles: o "Investimento em programas e/ou projetos externos" - ações programadas em benefício do meio ambiente com parceria com 
outras instituições, publicadas e privadas e o "Investimento relacionado com a produção/produção da empresa", evidenciando gastos em Programas e Projetos de Gestão Ambiental, prevenindo ou recuperando as agressões causadas por ela ao meio ambiente, em razão de sua atividade operacional.

Tabela 1: Indicadores de responsabilidade social voltados para o meio ambiente

\begin{tabular}{|c|c|c|c|c|c|c|c|c|c|c|c|c|c|c|c|}
\hline INDICADORES DE RESPONSABILIDADE SOCIAL & $\begin{array}{l}\infty \\
\stackrel{\infty}{\sigma} \\
\sigma\end{array}$ & ڤे & $\underset{\overbrace{}}{8}$ & $\bar{\delta}$ & 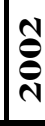 & ל్ֶ & 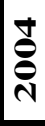 & |n & 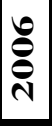 & $\begin{array}{l}\hat{\mathrm{N}} \\
\hat{\mathrm{N}}\end{array}$ & 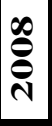 & $\begin{array}{l}\hat{\theta} \\
\stackrel{\sigma}{\sigma}\end{array}$ & $\begin{array}{l}\dot{\vdots} \\
\dot{0} \\
0\end{array}$ & $\%$ & 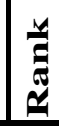 \\
\hline Total dos Investimentos em Meio Ambiente & $\mathrm{x}$ & $\mathrm{x}$ & $\mathrm{x}$ & $\mathrm{x}$ & $\mathrm{x}$ & $\mathrm{x}$ & $\mathrm{x}$ & $\mathrm{x}$ & $\mathrm{x}$ & $\mathrm{X}$ & $\mathrm{x}$ & $\mathrm{X}$ & 12 & 100,0 & $1^{\circ}$ \\
\hline Investimento em programas e/ou projetos externos & & & $\mathrm{x}$ & & $x$ & $\mathrm{x}$ & $\mathrm{X}$ & $\mathrm{x}$ & $\mathrm{x}$ & $\mathrm{x}$ & $\mathrm{x}$ & $\mathrm{x}$ & 9 & 75,0 & $2^{0}$ \\
\hline Investimento relacionados com a produção/operação & & & & $\mathrm{x}$ & $\mathrm{x}$ & $\mathrm{X}$ & $\mathrm{x}$ & $\mathrm{X}$ & $\mathrm{X}$ & $\mathrm{x}$ & $\mathrm{x}$ & $\mathrm{x}$ & 9 & 75,0 & $2^{\circ}$ \\
\hline
\end{tabular}

Fonte: Pesquisa documental, 2010.

A Tabela 2 evidencia que alimentação, educação, participação nos lucros, saúde e previdência privada foram apontados pela Petrobras como indicadores sociais durante todos os períodos estudados. O indicador "Creche e Auxilio-Creche" aparece em 11 dos 12 anos analisados. Já em 2000, todos os indicadores recebem investimentos até o final do período estudado. Faz-se necessário ressaltar que "Encargos sociais compulsórios" é uma obrigação legal e não deve caracterizar responsabilidade socioambiental.

Tabela 2: Indicadores de responsabilidade social feita para os funcionários

\begin{tabular}{|c|c|c|c|c|c|c|c|c|c|c|c|c|c|c|c|}
\hline INDICADORES DE RESPONSABILIDADE SOCIAL & ஓ̊ & Яু & ষ্ণ & ్ㅗㅇ & ్ㅗㅇ & ஜ̊ & ষ্ণ & 옹 & ஜ̊ & 용 & 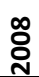 & ᄋ్ & òं & $\%$ & 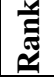 \\
\hline Alimentação & $\bar{x}$ & $x$ & $\bar{x}$ & $\mathrm{X}$ & $\mathrm{X}$ & $\mathrm{x}$ & $\mathrm{X}$ & $\bar{x}$ & $\mathrm{x}$ & $\mathrm{X}$ & $\bar{x}$ & $\mathrm{x}$ & 12 & 100,0 & $1^{\circ}$ \\
\hline Educação & $\mathrm{X}$ & $\mathrm{x}$ & $\mathrm{X}$ & $\mathrm{x}$ & $\mathrm{x}$ & $\mathrm{x}$ & $\mathrm{x}$ & $\mathrm{X}$ & $\mathrm{x}$ & $\mathrm{x}$ & $\mathrm{X}$ & $\mathrm{x}$ & 12 & 100,0 & $1^{\circ}$ \\
\hline Outros beneficios internos & $\mathrm{x}$ & $\mathrm{x}$ & $\mathrm{x}$ & $\mathrm{x}$ & $\mathrm{x}$ & $\mathrm{x}$ & $\mathrm{x}$ & $\mathrm{X}$ & $\mathrm{x}$ & $\mathrm{x}$ & $\mathrm{X}$ & $\mathrm{x}$ & 12 & 100,0 & $1^{\circ}$ \\
\hline Participação nos Lucros ou Resultados & $\mathrm{x}$ & $\mathrm{x}$ & $\mathrm{x}$ & $\mathrm{x}$ & $\mathrm{x}$ & $\mathrm{x}$ & $\mathrm{x}$ & $\mathrm{x}$ & $\mathrm{x}$ & $\mathrm{x}$ & $\mathrm{x}$ & $\mathrm{x}$ & 12 & 100,0 & $1^{\circ}$ \\
\hline Previdência Privada & $\mathrm{x}$ & $\mathrm{x}$ & $\mathrm{x}$ & $\mathrm{x}$ & $\mathrm{x}$ & $\mathrm{x}$ & $\mathrm{x}$ & $\mathrm{X}$ & $\mathrm{x}$ & $\mathrm{x}$ & $\mathrm{X}$ & $\mathrm{x}$ & 12 & 100,0 & $1^{\circ}$ \\
\hline Saúde & $\mathrm{x}$ & $\mathrm{x}$ & $\mathrm{x}$ & $\mathrm{x}$ & $\mathrm{x}$ & $\mathrm{x}$ & $\mathrm{x}$ & $\mathrm{x}$ & $\mathrm{x}$ & $\mathrm{x}$ & $\mathrm{x}$ & $\mathrm{x}$ & 12 & 100,0 & $1^{\mathrm{o}}$ \\
\hline Creches ou Auxilio-Creches & & $\mathrm{x}$ & $\mathrm{x}$ & $\mathrm{x}$ & $\mathrm{x}$ & $\mathrm{x}$ & $\mathrm{x}$ & $\mathrm{x}$ & $\mathrm{x}$ & $\mathrm{x}$ & $\mathrm{x}$ & $\mathrm{x}$ & 11 & 91,7 & $2^{\circ}$ \\
\hline Capacitação e Desenvolvimento Profissional & & & $\mathrm{x}$ & $\mathrm{x}$ & $\mathrm{x}$ & $\mathrm{x}$ & $\mathrm{x}$ & $\mathrm{x}$ & $\mathrm{x}$ & $\mathrm{x}$ & $\mathrm{x}$ & $\mathrm{x}$ & 10 & 83,3 & $3^{\circ}$ \\
\hline$\overline{\text { Cultura }}$ & & & $\mathrm{x}$ & $\mathrm{x}$ & $\mathrm{x}$ & $\mathrm{x}$ & $\mathrm{x}$ & $\mathrm{x}$ & $\mathrm{x}$ & $\mathrm{x}$ & $\mathrm{x}$ & $\mathrm{x}$ & 10 & 83,3 & $3^{\circ}$ \\
\hline Segurança + Medicina do Trabalho & & & $\mathrm{x}$ & $\mathrm{x}$ & $\mathrm{x}$ & $\mathrm{x}$ & $\mathrm{x}$ & $\mathrm{x}$ & $\mathrm{x}$ & $\mathrm{x}$ & $\mathrm{x}$ & $\mathrm{x}$ & 10 & 83,3 & $3^{\circ}$ \\
\hline INDICADORES (QUE NÃO SÃO DE RESPONSABILIDADE) & $\begin{array}{l}\infty \\
\text { ğ } \\
\end{array}$ & જू & 유 & 홍 & 옹 & 욤 & ষ্ণ & 농 & ஜ̊ & 옹 & 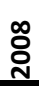 & 용 & ㅎํ․ & $\%$ & 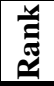 \\
\hline Encargos Sociais Compulsórios & $\mathrm{x}$ & $\mathrm{x}$ & $\mathrm{x}$ & $\mathrm{X}$ & $\mathrm{x}$ & $\mathrm{X}$ & $\mathrm{X}$ & $\mathrm{X}$ & $\mathrm{x}$ & $\mathrm{X}$ & $\mathrm{x}$ & $\mathrm{x}$ & 12 & 100,0 & $1^{\circ}$ \\
\hline
\end{tabular}

Fonte: Pesquisa documental, 2010

A tabela 3 apresenta os indicadores do Corpo Funcional. Admissões durante o período e o número de empregados aparecem em todos os 12 anos estudados. Em 1999, houve interesse em incluir dados sobre pessoas "especiais" como portadores de deficiente ou necessidades especiais, bem como o número de mulheres que trabalham na empresa e o \% delas em cargo de chefia. Somente em 2003 foi incluído o grupo de negros nessas categorias de indicadores. Os indicadores Números de empregados acima de 45 anos e Números de empregados terceirizados foram introduzidos a partir de 2000. 
Tabela 3: Indicadores sociais que evidenciam a gestão de pessoas

\begin{tabular}{|c|c|c|c|c|c|c|c|c|c|c|c|c|c|c|c|}
\hline INDICADORES DE RESPONSABILIDADE SOCIAL & $\begin{array}{l}\infty \\
\text { ğ } \\
-\end{array}$ & $\begin{array}{l}\text { م } \\
\text { बे } \\
\text { न }\end{array}$ & : & 옹 & : & 吕 & $\begin{array}{l}\text { ষ } \\
\text { ঠ } \\
\text { N }\end{array}$ & นn & $\begin{array}{l}0 \\
\stackrel{\text { D }}{0} \\
\end{array}$ & ̊̊̊ & $\begin{array}{l}\infty \\
\stackrel{\infty}{0} \\
\stackrel{N}{N}\end{array}$ & : & $\begin{array}{l}\dot{\circ} \\
\text { Oे }\end{array}$ & $\%$ & $\begin{array}{l}\mathscr{y} \\
\ddot{Z} \\
\ddot{\mathscr{Z}}\end{array}$ \\
\hline № de admissões durante o período & $\mathrm{x}$ & $\mathrm{x}$ & $\mathrm{x}$ & $\mathrm{x}$ & $\mathrm{x}$ & $\mathrm{x}$ & $\mathrm{x}$ & $\mathrm{x}$ & $\mathrm{x}$ & $\mathrm{x}$ & $\mathrm{x}$ & $\mathrm{x}$ & 12 & 100,0 & $1^{0}$ \\
\hline № de empregados(as) ao final do período & $\mathrm{x}$ & $\mathrm{x}$ & $\mathrm{x}$ & $\mathrm{x}$ & $\mathrm{x}$ & $\mathrm{x}$ & $\mathrm{x}$ & $\mathrm{x}$ & $\mathrm{x}$ & $\mathrm{x}$ & $\mathrm{x}$ & $\mathrm{x}$ & 12 & 100,0 & $1^{0}$ \\
\hline $\mathrm{n}^{0}$ de portadores de deficiência ou necessidades especiais & & $\mathrm{x}$ & $\mathrm{x}$ & $\mathrm{x}$ & $\mathrm{X}$ & $\mathrm{x}$ & $\mathrm{x}$ & $\mathrm{x}$ & $\mathrm{x}$ & $\mathrm{x}$ & $\mathrm{X}$ & $\mathrm{x}$ & 11 & 91,7 & $2^{\circ}$ \\
\hline № de mulheres que trabalham na empresa & & $\mathrm{x}$ & $\mathrm{x}$ & $\mathrm{x}$ & $\mathrm{x}$ & $\mathrm{x}$ & $\mathrm{x}$ & $\mathrm{x}$ & $\mathrm{x}$ & $\mathrm{x}$ & $\mathrm{x}$ & $\mathrm{X}$ & 11 & 91,7 & $2^{\circ}$ \\
\hline$\%$ de cargos de chefia ocupados por mulheres & & $\mathrm{x}$ & $\mathrm{x}$ & $\mathrm{x}$ & $\mathrm{x}$ & $\mathrm{x}$ & $\mathrm{x}$ & $\mathrm{x}$ & $\mathrm{x}$ & $\mathrm{X}$ & $\mathrm{x}$ & $\mathrm{x}$ & 11 & 91,7 & $2^{0}$ \\
\hline № de empregados (as) terceirizados(as) & & & $\mathrm{x}$ & $\mathrm{x}$ & $\mathrm{x}$ & $\mathrm{x}$ & $\mathrm{x}$ & $\mathrm{x}$ & $\mathrm{x}$ & $\mathrm{x}$ & $\mathrm{x}$ & $\mathrm{x}$ & 10 & 83,3 & $3^{\circ}$ \\
\hline № de empregados(as) acima de 45 anos & & & $\mathrm{x}$ & $\mathrm{x}$ & $\mathrm{x}$ & $\mathrm{x}$ & $\mathrm{x}$ & $\mathrm{x}$ & $\mathrm{x}$ & $\mathrm{X}$ & $\mathrm{X}$ & $\mathrm{x}$ & 10 & 83,3 & $3^{\circ}$ \\
\hline$\%$ de cargos de chefia ocupados por negros(as) & & & & & & $\mathrm{x}$ & $\mathrm{x}$ & $\mathrm{x}$ & $\mathrm{x}$ & $\mathrm{x}$ & $\mathrm{X}$ & $\mathrm{X}$ & 7 & 58,3 & $4^{0}$ \\
\hline № de negros (as) que trabalham na empresa & & & & & & $X$ & $\mathrm{x}$ & $\mathrm{X}$ & $\mathrm{x}$ & $\mathrm{x}$ & $\mathrm{X}$ & $\mathrm{x}$ & 7 & 58,3 & $4^{0}$ \\
\hline
\end{tabular}

Fonte: Pesquisa documental, 2010

A tabela 4 mostra o ranking dos indicadores sociais externos utilizados pelas Petrobras, que evidenciam investimentos desta empresa em ações voltadas para a sociedade de maneira geral. As descobertas da pesquisa demonstram: 2 (dois) dos indicadores descritos não são indicadores de responsabilidade socioambiental. São eles: Tributos Excluídos - encargos Sociais, e Tributos Provisionados- excluídos encargos sociais, já que eles são obrigações da empresa junto ao governo. Os demais são considerados como indicadores de responsabilidade socioambiental. Verifica-se, no $1^{\circ}$ lugar no ranking $(91,7 \%)$ o indicador denominado: total dos investimentos voltados para o publico externo. Em $2^{\circ}$ lugar, estão os indicadores educação e esporte. Em último lugar, no ranking dos indicadores: combate a fome e a segurança e garantia dos direitos da criança, com investimentos, de forma esporádica, durante o período estudado.

Tabela 4: Indicadores utilizados para demonstrar as ações de responsabilidade social feitas para a sociedade

\begin{tabular}{|c|c|c|c|c|c|c|c|c|c|c|c|c|c|c|c|}
\hline INDICADORES DE RESPONSABILIDADE SOCIAL & $\begin{array}{l}\infty \\
\hat{\sigma}\end{array}$ & $\hat{\hat{\theta}}$ & 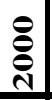 & 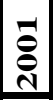 & 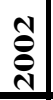 & $\begin{array}{l}m \\
\stackrel{\tilde{\sigma}}{0} \\
\end{array}$ & 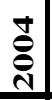 & 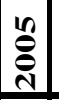 & 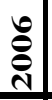 & 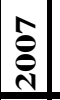 & 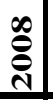 & $\begin{array}{l}\hat{\Theta} \\
\hat{\tilde{N}} \\
\end{array}$ & $\begin{array}{l}\dot{0} \\
\dot{0} \\
0\end{array}$ & $\%$ & 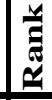 \\
\hline Total das contribuições para a sociedade & & $\mathrm{x}$ & $\mathrm{x}$ & $\mathrm{x}$ & $\mathrm{x}$ & $\mathrm{x}$ & $\mathrm{x}$ & $\mathrm{x}$ & $\mathrm{x}$ & $\mathrm{x}$ & $\mathrm{x}$ & $\mathrm{x}$ & 11 & 91,7 & $1^{0}$ \\
\hline \begin{tabular}{|l|l} 
Educação \\
\end{tabular} & & & $\mathrm{x}$ & $\mathrm{x}$ & $\mathrm{x}$ & $\mathrm{x}$ & $\mathrm{x}$ & $\mathrm{x}$ & $\mathrm{x}$ & $\mathrm{x}$ & $\mathrm{x}$ & $\mathrm{x}$ & 10 & 83,3 & $2^{\circ}$ \\
\hline Esporte & & & $\mathrm{x}$ & $\mathrm{x}$ & $\mathrm{x}$ & $\mathrm{x}$ & $\mathrm{x}$ & $\mathrm{x}$ & $\mathrm{x}$ & $\mathrm{x}$ & $\mathrm{x}$ & $\mathrm{x}$ & 10 & 83,3 & $2^{\circ}$ \\
\hline Cultura & & & $\mathrm{x}$ & & $\mathrm{x}$ & $\mathrm{x}$ & $\mathrm{x}$ & $\mathrm{x}$ & $\mathrm{x}$ & $\mathrm{x}$ & $\mathrm{x}$ & $\mathrm{x}$ & 9 & 75,0 & $3^{\circ}$ \\
\hline Saúde e saneamento & & & $\mathrm{x}$ & $\mathrm{x}$ & $\mathrm{x}$ & & $\mathrm{x}$ & $\mathrm{x}$ & & & & & 5 & 41,7 & $4^{\circ}$ \\
\hline Geração de trabalho e renda & & & & & & & & & $\mathrm{x}$ & $\mathrm{x}$ & $\mathrm{x}$ & $\mathrm{x}$ & 4 & 33,3 & $5^{\circ}$ \\
\hline Combate à fome e segurança alimentar & & & & & & $\mathrm{x}$ & $\mathrm{x}$ & $\mathrm{x}$ & & & & & 3 & 25,0 & $6^{\circ}$ \\
\hline Garantia dos direitos da Criança & & & & & & & & & $\mathrm{x}$ & $\mathrm{x}$ & $\mathrm{x}$ & & 3 & 25,0 & $7^{\circ}$ \\
\hline INDICADORES (QUE NÃO SÃO DE RESPONSABILIDADE) & $\begin{array}{l}\infty \\
\hat{\sigma}\end{array}$ & $\hat{\hat{\theta}}$ & 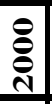 & है & 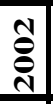 & ๕̊ & 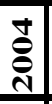 & 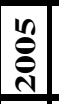 & 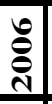 & 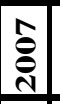 & 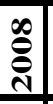 & 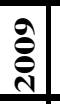 & $\begin{array}{l}\dot{0} \\
\dot{0}\end{array}$ & $\%$ & 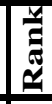 \\
\hline Tributos - excluídos encargos sociais & & & $\mathrm{x}$ & $\mathrm{x}$ & $\mathrm{x}$ & $\mathrm{x}$ & $\mathrm{x}$ & $\mathrm{x}$ & $\mathrm{x}$ & $\mathrm{x}$ & $\mathrm{x}$ & $\mathrm{x}$ & 10 & 83,3 & $1^{\circ}$ \\
\hline Tributos Provisionados (excluídos encargos Sociais) & & & $\mathrm{x}$ & $\mathrm{x}$ & & & & & & & & & 2 & 16,7 & $2^{\circ}$ \\
\hline
\end{tabular}

Fonte: Pesquisa documental, 2010

\subsection{Investimentos no público interno}

Em termos do valor investido em cada indicador referente ao público interno, a pesquisa (Figura 6) demonstra um destaque na aplicação de recursos destinados a ações em saúde, somente no período e 1998-2001. Após o exercício de 2001, os investimentos nas ações voltadas para os colaboradores foram focadas na área de previdência privada, com 
Evidenciação da aplicação do valor adicionado em ações de responsabilidade socioambiental: um estudo realizado com base nos balanços sociais da Petrobrás S.A. no período de 1998 a

destaque no período de 2001-2004. A partir desse ano, o investimento na previdência permanece mais ou menos estável até o final do período estudado. A partir de 2005, além da previdência, a empresa priorizou seus investimentos na área de Segurança e Medicina de Trabalho, cobrindo, assim, tanto a prevenção quanto a assistência à saúde.

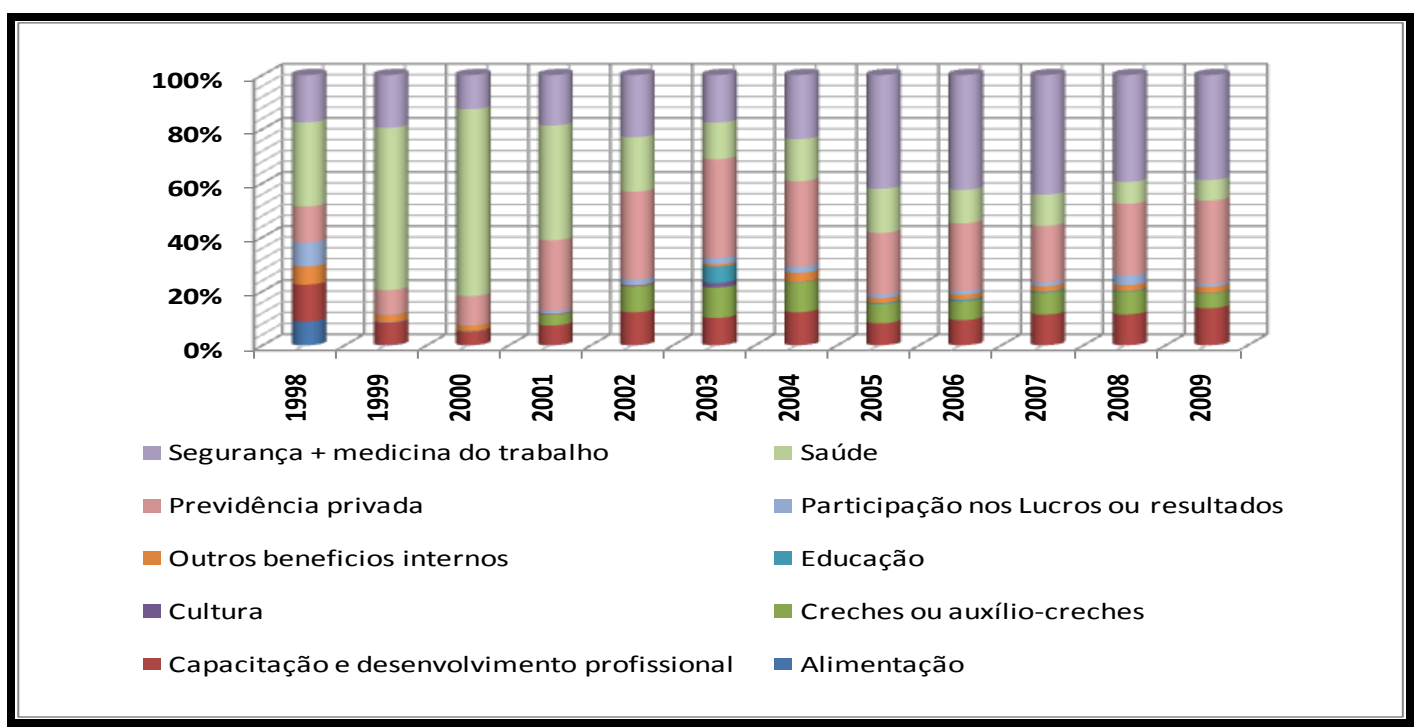

Figura 6: Investimento voltadas para o público interno

Fonte: Pesquisa documental, 2010

\subsection{Investimento no público externo}

A Figura 7 mostra as áreas de prioridade do investimento da empresa voltado para a sociedade, bem como o agente beneficiado. Os investimentos somente se referem ao exercício de 2003 em diante. Os resultados evidenciam que a maior parte da "riqueza gerada" foi destinada a ações ligadas à área da cultura, com destaque para 2003, em que a aplicação chegou, aproximadamente, a 75\% dos recursos destinados a este agente beneficiado (Vide Figura 7). Em termos de volume monetário investido, porém, o pico em cultura ocorreu em 2006, com a aplicação de R \$ 288.569,00 (Milhões). Em segundo lugar, aparecem os gastos com educação, se considerado o período de 2003 a 2009, e os gastos com garantia dos direitos da criança os últimos três exercícios estudados. 


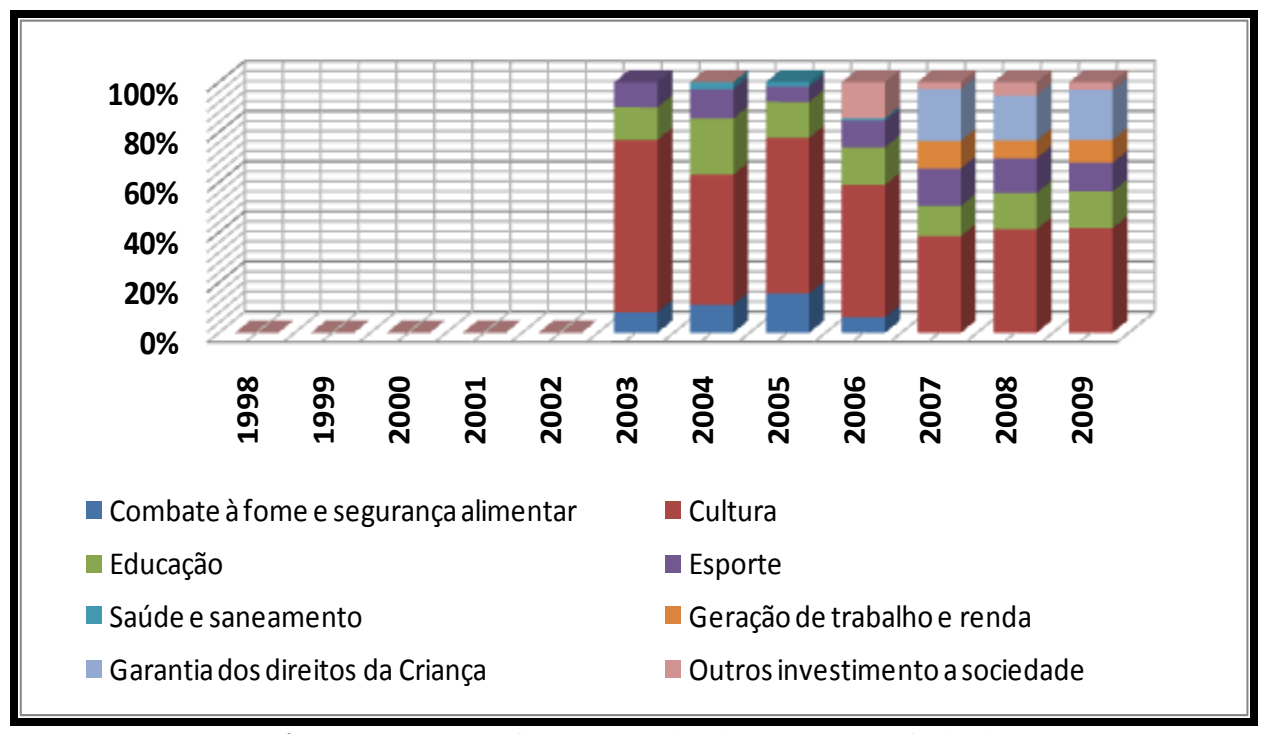

Figura 7: Investimento voltado para a sociedade

Fonte: Pesquisa documental, 2010

\subsection{Investimento no meio ambiente}

Diante da análise das figuras 8 e 9, nota-se que não foi evidenciada a quantidade de recursos aplicados na área ambiental nos dois primeiros anos, sejam por projetos desenvolvidos internamente, como externamente em parceria com outras empresas. A partir do exercício de 2000, verificou-se uma preocupação com investimentos relacionados com a produção /operação, com gastos variáveis entre 95 a 100\% dos gastos até o final do período estudado.

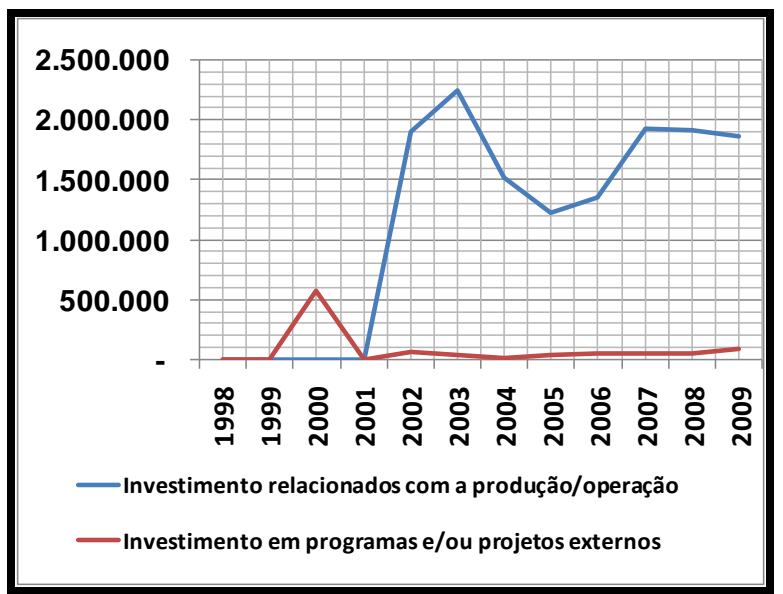

Figura 8: Evolução monetária na área ambiental Fonte: Pesquisa documental, 2010

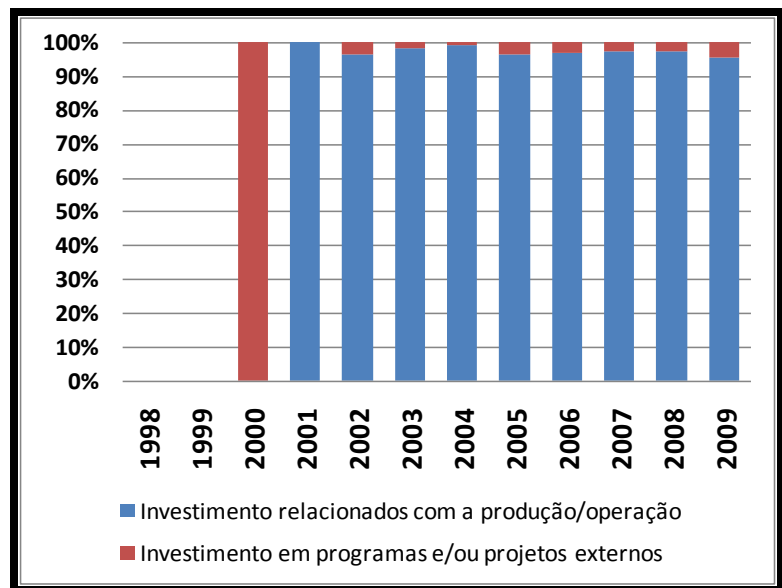

Figura 9: Investimentos na área ambiental. Fonte: Pesquisa documental, 2010

\section{CONSIDERAÇÕES FINAIS}

Um dos objetivos desta pesquisa foi verificar quanto da "riqueza gerada" é aplicado em projetos de ações sociais pela Petrobras S.A. Este estudo constatou que esta aplicação chega, em média, à 5\% do valor adicionado, no período estudado de 1998 a 2009. O maior agente beneficiado com parte dessa riqueza é o funcionário, com destaque nas áreas de segurança e medicina do trabalho, saúde e previdência privada.

O segundo agente beneficiado é a sociedade, com uma média de consumo em torno de $1,5 \%$, com ações destacadas por meio das áreas de cultura, educação e garantia dos direitos da criança, embora a última área de ação somente esteve presente em projetos no final do período de 2006 a 2008. A grande aplicação da Petrobras em ações voltadas à Cultura se deve a Lei Federal de 
Evidenciação da aplicação do valor adicionado em ações de responsabilidade socioambiental: um estudo realizado com base nos balanços sociais da Petrobrás S.A. no período de 1998 a

Incentivo à Cultura (Lei no 8.313 de 23 de dezembro de 1991), conhecida também por Lei Rouanet. Esta lei possibilita as empresas aplicarem 4\% do IR (imposto de renda) devido em ações culturais.

Verificou-se que o meio ambiente é o agente menos beneficiado das ações sociais da Petrobras S.A. Para se ter uma ideia, a fatia do valor investido foi menos de $0,5 \%$ do valor adicionado gerado durante o período de 1998 a 2009. Esse parâmetro chamou a atenção pelo fato de se esperar que a Petrobras investisse mais recursos na área ambiental, em razão dos riscos que sua atividade operacional pode gerar para o meio ambiente.

Em resumo, a Petrobras vem distribuindo pouco de sua riqueza gerada para atividades voltadas para o Social, principalmente na questão do meio ambiente, uma vez que ela é uma das empresas brasileiras cuja atividade traz riscos e impactos ambientais significativos.

Recomenda-se para futuras pesquisas a utilização de relatórios de sustentabilidade que façam uso da metodologia da GRI. Esses relatórios apresentam também informações qualitativas que poderiam complementar os dados quantitativos analisados.

\section{REFERÊNCIAS}

Cervo, A.L., Bervian, P.A.(2006) Metodologia científica. (6ª ed.) São Paulo: Prentice Hall,.

Chan, B.L.; Silva, F.L. da; Martins, G. de A.( Out/Dez., 2007) Destinação de riqueza aos acionistas e aos empregados: comparação entre empresas estatais e privadas. Revista de Administração Contemporânea, 11(4), 199-218.

Correia, F.T. de B.S., Medeiros, J.R.C. (2003) Responsabilidade social corporativa para quem? In Responsabilidade social das empresas: a contribuição das universidades, v. II. (2 $2^{\text {a }}$ E). São Paulo: Peirópolis: Instituto Ethos.

Cosenza. J.P. (Out, 2003) A eficácia informativa da demonstração do valor adicionado. Revista Contabilidade \& Finanças. São Paulo, Edição comemorativa, 7-30.

Custódio, A.L. de M., Moya, R. (2007) Ethos. Guia para Elaboração de Balanço Social e Relatórios de Sustentabilidade 2007. São Paulo: Instituto Ethos.

Cunha, J.V.A. da, Oliveira, M.C.; De Luca, M.M.M. (2009) Demonstrações do valor adicionado: do cálculo da riqueza criada pela empresa ao valor do PIB. (2 ${ }^{\mathrm{a}}$ ed.) São Paulo: Atlas.

Estadão.(2010) Petrobrás pode se tornar a quarta maior empresa do mundo. 25 de set.

Hatz, M.C. (2001) Critérios essenciais à implantação da social accountability (AS) 8000: um estudo de caso. Florianópolis: UFSC.

Hopwood, A., Burchell, S. (1982) La Contabilidad social em El Reino Unido. In: El balance social de la empresa y de lãs instituciones financeiras. Madrid: Banco de Bilbao, 459-476. (1as Jornadas de Estudio sobre Econcomia y sociedad)

Instituto Brasileiro de Análises Sociais e Econômicas (Ibase).(2008) Dez anos de Balanço Social: o desafio da transparência. Rio de Janeiro: IBASE. 
Landim, R .(2010) Petrobrás se expande em várias áreas e já movimenta 10\% do PIB. Estadão, 30 de Janeiro.

Kroetz, C.E.S. (maio/jun, 2001) Balanço social: uma proposta de normatização. Revista Brasileira de Contabilidade. Brasília, (120).

Marconi, M.A., Lakatos, E.M.(2003) Fundamentos de Metodologia Científica. (5 a ed.) São Paulo: Atlas.

Martins, G.de A.(2008) Estudo de caso: uma estratégia de pesquisa. (2a ed.) São Paulo: Atlas.

Mendonça, F.(set,2004) O que é Responsabilidade Social. Revista FAE BUSINESS, (9).

Reis, C.N. dos; Medeiros, L.E.(2007) Responsabilidade social das empresas e balanços social: meios propulsores do desenvolvimento econômico e social. São Paulo: Atlas.

Rizzi, F.B.(2002) Balanço social e ação de responsabilidade social nas empresas. In: Instituto Ethos: Prêmio Ethos Valor. Vários autores. Responsabilidade social das empresas: a contribuição das universidades. São Paulo: Editora Fundação Petrópolis.

Tinoco, J.E.P. (1984) Balanço Social: uma abordagem sócio-econômica da contabilidade. 1984. Dissertação de Mestrado, Faculdade de Economia, Administração e Contabilidade da Universidade de São Paulo, São Paulo.

Torres, C. (2002) Responsabilidade social das empresas (RSE) e balanço social no Brasil. In: Silva, C.A.T., Freire, F. de S. (Org.). Balanço social: teoria e prática. São Paulo: Atlas.

Vergara, S.C. (2000) Projetos e relatórios de pesquisa em administração. (3 ${ }^{\mathrm{a}}$ ed.) São Paulo: Atlas. 
Evidenciação da aplicação do valor adicionado em ações de responsabilidade socioambiental: um estudo realizado com base nos balanços sociais da Petrobrás S.A. no período de 1998 a

Data do recebimento do artigo: 22/03/2012

Data do aceite de publicação: 10/08/2012 